\title{
Tuberculous lymphadenitis in Manitoba: Incidence, clinical characteristics and treatment
}

\author{
Victoria J Cook MD FRCPC, Jure Manfreda MD, Earl S Hershfield MD FRCPC
}

VJ Cook, J Manfreda, ES Hershfield. Tuberculous lymphadenitis in Manitoba: Incidence, clinical characteristics and treatment. Can Respir J 2004;11(4):279-286.

BACKGROUND: Tuberculous lymphadenitis (TBL) is an important form of extrapulmonary tuberculosis (TB). Recent studies have shown an increase in TBL in Canada.

OBJECTIVES: To determine the incidence of TBL in Manitoba and to identify the characteristics associated with its presentation, diagnosis and treatment

METHODS: Population data from the Manitoba Health Population Registry, the First Nations and Inuit Health Branch of Health Canada, and Statistics Canada were used to calculate incidence. Case characteristics and outcomes were determined by a systematic, retrospective review of all cases between January 1, 1990 and December 31, 2000.

RESULTS: One-hundred forty seven cases of TBL were identifiedduring the study period; $77 \%$ confirmed by culture; $68 \%$ women. TBL was found in Canadian-born/nonstatus Aboriginal (12\%), status Aboriginal (29\%) and foreign-born (59\%) populations. Incidence of TBL was 1.17 per 100,000 person years (95\% CI 0.98 to 1.36 ). The highest incidence was in status Aboriginals over 65 years (16.85 per 100,000 person years; $95 \%$ CI 3.37 to 30.33 ). TBL is seen most often in Western Pacific women. The most common presentation was a single, enlarged cervical node (80\%). No atypical mycobacterium was found. Drug resistance occurred in $13 \%$ of cases and only in the foreign-born. Cure rates $(81 \%)$ were influenced by comorbidity and burden of TB disease. Relapse occurred in 8.1 per 1000 person years of follow-up (95\% CI 1.7 to 23.7).

CONCLUSIONS: Respiratory physicians, who manage the majority of TB disease in Canada, need to remain aware that TB is an important and treatable cause of enlarged lymph nodes.

Key Words: Extrapulmonary tuberculosis; Scrofula; Tuberculous lymphadenitis

$\mathrm{O}$ ne-third of the world's population is currently infected with tuberculosis (TB) and $5 \%$ to $10 \%$ of these people will become sick or infectious at some time during their life (1). According to the World Health Organization (WHO), breakdowns in health services, an increase in mobile and displaced populations, the spread of human immunodeficiency virus (HIV) infection and the emergence of multi-drug resistant TB may be responsible for this growing global epidemic (2).

\section{Adénite tuberculeuse au Manitoba : préva- lence, caractéristiques cliniques et traitement}

CONTEXTE : L'adénite tuberculeuse (AT) est une forme grave de tuberculose (TB) extrapulmonaire. Selon des études, l'AT est à la hausse au Canada.

OBJECTIFS : Déterminer la fréquence de l'AT au Manitoba et préciser les caractéristiques associées au tableau clinique, au diagnostic et au traitement.

MÉTHODE : Des données tirées du Manitoba Health Population Registry, de la Direction générale de la santé des Premières nations et des Inuits de Santé Canada, et de Statistique Canada ont servi à calculer la prévalence de la maladie. L'étude des caractéristiques et des résultats s'est faite à partir d'un examen systématique et rétrospectif de tous les cas relevés entre le $1^{\mathrm{er}}$ janvier 1990 et le 31 décembre 2000.

RÉSULTATS : Cent quarante sept cas d'AT ont été dénombré pour la période à l'étude ( $77 \%$ : confirmés par des cultures; $68 \%$ : enregistrés chez des femmes). Les chiffres se lisaient comme suit : $12 \%$ chez les Canadiens de naissance et les Autochtones non inscrits; $29 \%$ chez les Autochtones inscrits; $59 \%$ chez les Canadiens nés à l'étranger. La prévalence de l'AT s'est établie à 1,17 par 100000 années-personnes (AP) (intervalle de confiance [IC] à $95 \%$ : 0,98-1,36). La fréquence la plus élevée a été enregistrée chez les Autochtones inscrits de plus de 65 ans (16,85 par 100000 AP; IC à $95 \%$ : 3,37-30,33). L'AT se rencontre surtout chez les femmes demeurant sur la côte ouest du Pacifique. La manifestation la plus fréquente était la tuméfaction d'un seul ganglion du cou (80\%). Aucune bacille (Mycobacterium) atypique n'a été trouvée. Une pharmaco-résistance a été observée dans $13 \%$ des cas et uniquement chez les personnes nées à l'étranger. Les taux de guérison (81\%) variaient en fonction des maladies concomitantes et du degré de gravité de la TB. Il y a eu rechute dans 8,1 cas par 1000 années-personnes de suivi (IC à $95 \%$ : 1,723,7).

CONCLUSION : Les pneumologues, qui traitent la plupart des cas de TB au Canada, doivent se rappeler que la TB constitue une cause importante mais traitable de tuméfaction ganglionnaire.

University of Manitoba, Health Sciences Centre, Winnipeg, Manitoba

Correspondence: Dr Victoria J Cook, Division of TB Control, BC Centre for Disease Control, 655 West 12th Avenue,

Vancouver, British Columbia V5Z 4R4. Telephone 604-660-6127, fax 604-660-1950, e-mail victoria.cook@bccdc.ca 
status Aboriginal population (43\%; 28.9 per 100,000 person years) followed by the foreign-born $(33 \% ; 23.1$ per 100,000 person years) $(3,4)$.

Tuberculous lymphadenitis (TBL) is an important form of extrapulmonary TB (5). In Manitoba, 20\% to 30\% of reported TB cases are extrapulmonary while TBL makes up approximately $13 \%$ of all TB cases (4). Recent studies have shown an increase in proportion of extrapulmonary $\mathrm{TB}$ cases due to TBL in Canada $(6,7)$. This may reflect the ethnic origin of reported cases of TBL because the proportion of all TB cases in Canada that is foreign-born is rising and TBL has often been reported in young Asian women (5,6,8-10). The increased proportion of foreign-born cases of all TB reflects the shift in immigration to Canada from low prevalence (European) to high prevalence (Asian) TB countries (11). Our objective was to perform a retrospective, population-based study of TBL to determine the incidence of disease in Manitoba between January 1, 1990, and December 31, 2000, and to identify characteristics associated with its presentation, diagnosis and treatment.

\section{Case identification}

\section{METHODS}

All cases of TB are reported to a central TB registry in Manitoba. This registry collects demographic and epidemiological data as well as documents the treatment and outcome for all TB cases. There were 154 cases of TBL identified through the registry files during the study period (4). Both new active and relapsed cases were included for review; seven cases were coded in error and were excluded from the study. Thus, 147 cases were included in the analysis.

All TB cultures in Manitoba are performed at a provincial laboratory with the results forwarded to the central TB registry. The exact methodology followed at our laboratory has been described in detail elsewhere (12). Cultures were considered positive if growth was detected by solid or liquid media. Positive cultures were identified using commercial DNA probes complementary to species-specific rRNA. Since DNA probes are unable to distinguish between members of the Mycobacterium tuberculosis complex, differentiation relies on the phenotypic characteristics of biochemical testing, pigment production, growth characteristics and colonial morphology (13). It is clinically relevant to differentiate $\mathrm{M}$ tuberculosis complex probe-positive isolates. Niacin production, nitrate reduction, susceptibility to thiophen-2-carboxylic acid hydrazide and pyrazinamide, and detection of pyrazinamidase activity were used to differentiate $\mathrm{M}$ tuberculosis from $\mathrm{M}$ bovis. The extent of biochemical testing depended on the ease of characterization and biochemical activity of the mycobacterium under investigation. Cases with Mycobacterium bovis-bacille CalmetteGuérin strains were excluded from the study.

The diagnosis of TBL for this study was based on culture and/or pathology from a lymph node source or on clinical grounds alone. Culture results could have been obtained from lymph node drainage swab, fine-needle aspirate (FNA) or tissue biopsy. If granulomatous inflammation was present within identifiable lymph node tissue, pathology was recorded as positive (5). Those cases diagnosed on clinical grounds had documented positive Mantoux tests (equivalent to $10 \mathrm{~mm}$ ), cervical lymphadenopathy and clinical response to antituberculous treatment.

\section{Population}

The population of Manitoba was divided into three categories: Canadian-born/nonstatus Aboriginal (80\%), status Aboriginal (8\%) and foreign-born (12\%). For this study, status Aboriginal defined the Aboriginal or First Nations population with treaty numbers residing on and off reservation. The age and sex distribution of the Manitoba population for each year of our study, 1990 to 2000, was obtained from the Manitoba Health Population Registry (Manitoba Centre for Health Policy). The same information for status Aboriginals was obtained from the First Nations and Inuit Health Branch of Health Canada. The proportion of foreign-born by age and sex was estimated from Statistics Canada census years 1991 and 1996. These proportions were used to estimate the number of foreign-born in Manitoba. The Canadianborn/nonstatus Aboriginal population included those people remaining from the total population of Manitoba after subtracting the status Aboriginal and foreign-borns.

\section{Case characteristics and treatment}

We performed a population-based, systematic retrospective review of all cases of TBL identified in Manitoba during the study period. Demographic information such as date of birth, sex, ethnic origin, date of immigration and country of origin as well as history of TB was obtained from the central TB registry. The hospital chart and laboratory reports were also reviewed for information on the clinical characteristics, comorbid features, pathology, treatment and outcomes. Each case of TBL was classified according to the site and the number of lymph nodes involved and the presence or absence of concurrent, non-nodal TB disease. For cases with multiple episodes of TBL over the study period, the earliest episode was defined as the initial episode. Symptoms and their duration were recorded as lymph node specific (swelling, pain, drainage and/or ulceration), constitutional (fever, night sweats and weight-loss) or other (for example, respiratory or gastrointestinal). Comorbid features included HIV infection, diabetes mellitus, renal disease, malignancy and immunosuppressive therapy.

The TB registry maintains records of all prescribed medications by drug name and duration. First-line (isoniazid, rifampin, ethambutol, pyrazinamide and streptomycin) and second-line medications were documented. Medication taken for less than 30 days did not count towards treatment. Standard treatment for TBL consisted of at least three first-line drugs for the initial two months of a minimum six month duration of therapy as outlined by treatment guidelines (14-17). Nonstandard treatment included use of second-line drugs (ciprofloxacin, ethionamide, rifabutin, capreomycin and clofazimine), less than three drugs, or the duration of treatment of less than six months. Outcomes were divided into cures and noncures. Cases that adhered to at least $80 \%$ of scheduled treatment doses with clinical evidence of nodal regression were considered cured (18). Noncures included incomplete treatment (less than $80 \%$ of scheduled treatment doses), treatment failure (recurrent disease within six months of treatment completion), and death during treatment. Cases with recurrent disease more than six months after cure were defined as relapses.

The mycobacteriology of TBL was reviewed through culture and sensitivity reports. Drug resistance was identified as single or multiple. 
TABLE 1

Age and sex specific incidence rates (IRs) per 100,000 person years for tuberculous lymphadenitis, January 1, 1990, to December 31, 2000

\begin{tabular}{|c|c|c|c|c|c|c|c|c|c|}
\hline & \multicolumn{3}{|c|}{ Men } & \multicolumn{3}{|c|}{ Women } & \multicolumn{3}{|c|}{ Total } \\
\hline & $\mathbf{n}$ & IR & $95 \% \mathrm{Cl}$ & $\mathrm{n}$ & IR & $95 \% \mathrm{Cl}$ & $\mathbf{n}$ & IR & $95 \% \mathrm{Cl}$ \\
\hline \multicolumn{10}{|l|}{ Age (years) } \\
\hline $0-14$ & 4 & 0.29 & $0.01-0.57$ & 6 & 0.45 & $0.09-0.81$ & 10 & 0.37 & $0.14-0.59$ \\
\hline $15-34$ & 18 & 0.97 & $0.52-1.42$ & 33 & 1.81 & $1.19-2.43$ & 51 & 1.39 & $1.00-1.77$ \\
\hline $35-44$ & 8 & 0.81 & $0.25-1.38$ & 19 & 1.94 & $1.07-2.82$ & 27 & 1.38 & $0.86-1.90$ \\
\hline $45-64$ & 11 & 0.88 & $0.36-1.40$ & 23 & 1.82 & $1.08-2.57$ & 34 & 1.35 & $0.90-1.81$ \\
\hline $65+$ & 6 & 0.85 & $0.17-1.53$ & 19 & 1.94 & $1.07-2.82$ & 25 & 1.48 & $0.90-2.06$ \\
\hline Crude IR & 47 & 0.76 & $0.54-0.98$ & 100 & 1.57 & $1.26-1.88$ & 147 & 1.17 & $0.98-1.36$ \\
\hline Age-adjusted IR & & 0.76 & $0.54-0.98$ & & 1.56 & $1.25-1.86$ & & & \\
\hline
\end{tabular}

TABLE 2

Age and Table 2: Age and ethnic specific incidence rates (IRs) per 100,000 person years for tuberculous lymphadenitis, January 1, 1990, to December 31, 2000

\begin{tabular}{|c|c|c|c|c|c|c|c|c|c|}
\hline & \multicolumn{3}{|c|}{ Canadian-born/nonstatus Aboriginal } & \multicolumn{3}{|c|}{ Status Aboriginal } & \multicolumn{3}{|c|}{ Foreign-born } \\
\hline & $\mathbf{n}$ & IR & $95 \% \mathrm{Cl}$ & $\mathbf{n}$ & IR & $95 \% \mathrm{Cl}$ & $\mathbf{n}$ & IR & $95 \% \mathrm{Cl}$ \\
\hline \multicolumn{10}{|l|}{ Age (years) } \\
\hline $0-14$ & 3 & 0.13 & $0.00-0.28$ & 3 & 0.84 & $0.00-1.79$ & 4 & 5.08 & $0.10-10.07$ \\
\hline $15-34$ & 1 & 0.03 & $0.00-0.10$ & 11 & 2.95 & $1.21-4.69$ & 39 & 12.72 & $8.73-16.71$ \\
\hline $35-44$ & 2 & 0.13 & $0.00-0.31$ & 6 & 4.96 & $0.99-8.92$ & 19 & 6.62 & $3.64-9.59$ \\
\hline $45-64$ & 7 & 0.36 & $0.09-0.63$ & 17 & 15.33 & $8.04-22.62$ & 10 & 2.10 & $0.80-3.41$ \\
\hline $65+$ & 5 & 0.38 & $0.05-0.71$ & 6 & 16.85 & $3.37-30.33$ & 14 & 4.24 & $2.02-6.47$ \\
\hline Crude IR & 18 & 0.18 & $0.11-0.28$ & 43 & 4.30 & $3.12-5.80$ & 86 & 5.82 & $5.08-8.59$ \\
\hline Age- and sex-adjusted IR & & 0.18 & $0.11-0.29$ & & 7.27 & $4.90-10.26$ & & 6.70 & $4.99-8.40$ \\
\hline
\end{tabular}

Ethics

Ethics approval was obtained from the University of Manitoba Health Research Ethics Board and by the Health Sciences Centre Research Impact Committee.

\section{Statistics}

In addition to descriptive statistical methods, we estimated crude and adjusted incidence rates with 95\% CI limits using SAS (SAS Institute Inc, USA) and STATA software (Stata Corporation, USA). We estimated the incidence for the total population of Manitoba and for the subgroups defined by sex, age and ethnic origin. Incidence rates were adjusted using the direct method and the total Manitoba population as the reference.

\section{RESULTS}

\section{Incidence}

The number of TBL cases in Manitoba during the study period was 147 . The diagnosis of TBL was made by positive culture and pathology results $(n=60)$, culture positive only $(n=54)$, pathology positive only $(n=20)$, and clinical diagnosis $(n=13)$. Of all cases, 100 were women (68\%) and 47 were men (32\%). The age range was from one to 98 years. Almost $60 \%$ of cases were over the age of 35. Canadian-born/nonstatus Aboriginal, status Aboriginal, and foreign-born populations made up 12\%, $29 \%$ and $59 \%$ of the TBL cases, respectively.
The incidence of TBL in Manitoba was 1.17 cases (95\% CI $0.98-1.36$ ) per 100,000 person years (Table 1). The incidence in women was approximately twice that of men. It was the lowest for both sexes less than 15 years of age and rose to a peak incidence between 15 to 34 years of age for men and 35 to 44 years of age for women. The highest incidence of TBL was seen in the status Aboriginal population over 45 years old followed by the foreign-born between 15 and 34 years of age (Table 2). Using the age and sex adjusted incidence rates, status Aboriginals were 40.1 times (95\% CI 22.4-71.7) and the foreign-born were 36.9 times (95\% CI 21.8-62.6) as likely to develop TBL than Canadian-born/nonstatus Aboriginal population.

Over the study period, cases of TBL fluctuated from a low of eight cases in 1990 and 1993, to a high of 17 cases in 1999. Yearly incidence ranged from 0.7 (1990 and 1993) to 1.5 (1999) per 100,000 population and was higher in women, except in 1993 when there was an equivalent incidence for both sexes. Overall, the incidence of TBL in Manitoba remained stable during the study period.

Foreign-born cases were grouped by the WHO regions. Of all foreign-born cases, 79\% were from the Western Pacific region, $8 \%$ were from South-East Asia, and 5\% were from the Eastern Mediterranean region. Europe, the Americas and Africa made up 3\%, 2\% and 2\% of foreign-born cases, respectively. The most common countries of origin in the Western Pacific were the Philippines, Vietnam, Laos and China. 
TABLE 3

Lymph node location and symptoms at presentation $(n=147)$

\begin{tabular}{lcc}
\hline & $\mathbf{n}$ & $\%^{*}$ \\
\hline Location & 111 & 76 \\
Cervical & 39 & 27 \\
Supraclavicular & 14 & 10 \\
Axillary & 9 & 6 \\
Inguinal & 9 & 6 \\
Intra-abdominal & 6 & 4 \\
Mediastinal & 8 & 5 \\
Unknown & & \\
Symptoms: Lymph node & 121 & 82 \\
Swelling & 32 & 22 \\
Pain & 16 & 11 \\
Drainage & 6 & 4 \\
Ulceration & & \\
Symptoms: Other & 25 & 17 \\
Constitutional & 24 & 16 \\
Other &
\end{tabular}

*Percentages add up to greater than $100 \%$ because some patients had multiple nodal sites and symptoms

\section{Case characteristics}

Of 147 cases, TBL was most often present without TB elsewhere $(82 \%)$. Out of these 121 cases, $80 \%$ involved a single lymph node site. The most common location for a lymph node was in the cervical region and the most predominant symptom was swelling (Table 3 ). The duration of symptoms before diagnosis ranged from one to 120 months. When TB was confined to the lymph nodes, we found only $15 \%$ of the cases ( 18 of 121 cases) with multiple lymph node sites involved. However, when TBL was associated with TB elsewhere, multiple site lymphadenopathy was found in $58 \%$ of the cases ( 15 of 26 cases). To note, head and neck lymphadenopathy involved multiple sites if both the cervical and supraclavicular regions were involved. TBL was found with active TB elsewhere in $18 \%$ of the cases: respiratory TB in $8 \%$, nonrespiratory/non-nodal TB in $8 \%$, and both respiratory and nonrespiratory/non-nodal $\mathrm{TB}$ in $2 \%$ of cases.

A history of TB was documented in only 10\% of TBL cases. Comorbidity was documented in $26 \%$ of cases: $16 \%$ with a single comorbidity and $10 \%$ with multiple comorbidities. The most common comorbidities were renal disease $(15 \%)$ and diabetes mellitus (11\%). The status Aboriginal cases had the highest proportion of comorbidity (51\%) followed by the Canadian-born/nonstatus Aboriginal (33\%) and foreign-born $(12 \%)(\mathrm{P}<0.0001)$. The combination of renal disease and diabetes was found in $23 \%$ of the status Aboriginal cases (10 of 43 cases), in comparison with none in the Canadian-born/nonstatus Aboriginal cases. We documented six cases of HIV infection out of 40 test results available.

Bacteriological confirmation was obtained for 114 cases (78\%); 113 were $\mathrm{M}$ tuberculosis and one M bovis (Table 4). The proportion of culture-positive cases in the status Aboriginal population was greater than the foreign-born (93\% versus $72 \%$, $\mathrm{P}=0.006)$ and the Canadian-born/nonstatus Aboriginal $(93 \%$
TABLE 4

Bacteriology and drug resistance in tuberculous lymphadenitis, January 1, 1990, to December 31, 2000 $(n=147)$

\begin{tabular}{|c|c|c|c|}
\hline $\begin{array}{r}\mathrm{Ca} \\
\text { nonst }\end{array}$ & $\begin{array}{l}\text { ladian-born/ } \\
\text { atus Aboriginal }\end{array}$ & $\begin{array}{c}\text { Status } \\
\text { Aboriginal }\end{array}$ & $\begin{array}{l}\text { Foreign- } \\
\text { born }\end{array}$ \\
\hline Total cases $(\mathrm{n})$ & 18 & 43 & 86 \\
\hline Total cultures $(n)^{\star}$ & 12 & 40 & 62 \\
\hline Bacteriological confirmation (\%) & 67 & 93 & 72 \\
\hline Total sensitive $(n)^{\dagger}$ & 11 & 40 & 47 \\
\hline Drug resistance (\%) & 0 & 0 & 24 \\
\hline Total resistant (n) & 0 & 0 & 15 \\
\hline \multicolumn{4}{|l|}{ Monoresistance } \\
\hline INH & 0 & 0 & 3 \\
\hline PZA & 0 & 0 & $1^{\dagger}$ \\
\hline Strep & 0 & 0 & 6 \\
\hline \multicolumn{4}{|l|}{ Multiple drug resistance } \\
\hline $\mathrm{INH}+$ Strep & 0 & 0 & 3 \\
\hline $\mathrm{INH}+\mathrm{EMB}$ & 0 & 0 & 1 \\
\hline $\mathrm{INH}+\mathrm{EMB}+$ Strep & 0 & 0 & 1 \\
\hline
\end{tabular}

*Based on 114 positive cultures (all Mycobacterium tuberculosis except 1 Mycobacterium bovis); ${ }^{\dagger}$ Based on 113 sensitivity results. EMB Ethambutol; INH Isoniazid; PZA Pyrazinamide; Strep Streptomycin

versus $67 \%, \mathrm{P}=0.015)$ populations. There was no difference in bacteriological confirmation between the foreign-born and Canadian-born/nonstatus Aboriginal populations ( $72 \%$ versus $67 \%, \mathrm{P}=0.78$ ). Sensitivity results were available for all but one isolate. Drug resistance was seen only in the foreign-born and resistance to rifampin was not detected (Table 4).

\section{Treatment}

Eighteen cases were excluded from the outcome analysis: 12 cases were lost to follow-up, three were diagnosed postmortem, two refused treatment and one case had ongoing treatment at the time of data collection. Of the remaining 129 cases, the overall cure rate for TBL was $81 \%$ (Table 5) and did not significantly differ between ethnic groups $(\mathrm{P}=0.21)$. If comorbidity was associated with active TB elsewhere, the cure proportion was lower, although not significantly ( $\mathrm{P}=0.8$, Table 5$)$. All cases that died $(n=8)$ were treated with a nonstandard regimen, $75 \%$ were over the age of 60 years and $50 \%$ involved TB disease elsewhere. TB likely contributed to these deaths in all but two cases; one patient died of an acute myocardial infarction and the other died of a concomitant malignancy. To note, all $\mathrm{M}$ tuberculosis isolates from these cases were fully sensitive.

Most TBL cases $(65 \%)$, received standard treatment regimen. Nonstandard treatment included cases where secondline drugs were given $(5 \%)$, less than three drugs were used (26\%) or the total duration of treatment was less than six months (4\%). The cure rate for the cases that received standard treatment was significantly higher than those on nonstandard treatment $(88 \%$ versus $67 \%$ respectively; $\mathrm{P}<0.05)$. There were three treatment failures $(2.3 \%, 95 \%$ CI 0.5 to 6.6$)$ each with an initial episode of TBL alone with no identified comorbidity and fully sensitive organisms. Two out of the three cases were retreated till they were cured and the third was lost to follow-up. 
TABLE 5

Influence of clinical presentation and comorbidity on outcome of tuberculous lymphadenitis $(n=129)^{*}$

\begin{tabular}{|c|c|c|c|c|c|c|c|c|c|}
\hline \multirow{3}{*}{$\begin{array}{l}\text { Clinical presentation } \\
\text { Lymph node alone }\end{array}$} & \multirow{3}{*}{$\begin{array}{c}\text { Total } \\
n\end{array}$} & & & \multicolumn{6}{|c|}{ Noncures } \\
\hline & & \multicolumn{2}{|c|}{ Cures $^{\dagger}$} & \multicolumn{2}{|c|}{ Death } & \multicolumn{2}{|c|}{ Incomplete treatment } & \multicolumn{2}{|c|}{ Treatment failures } \\
\hline & & $\mathrm{n}$ & $\%$ & $\mathrm{n}$ & $\%$ & $\mathrm{n}$ & $\%$ & $n$ & $\%$ \\
\hline \multicolumn{10}{|l|}{ Comorbidity present } \\
\hline $\mathrm{No}^{\ddagger}$ & 82 & 67 & 82 & 1 & 1 & 11 & 13 & 3 & 4 \\
\hline Yes $^{\ddagger}$ & 26 & 21 & 81 & 3 & 12 & 2 & 8 & 0 & 0 \\
\hline \multicolumn{10}{|l|}{ Lymph node and other } \\
\hline \multicolumn{10}{|l|}{ Comorbidity present } \\
\hline No $\ddagger$ & 16 & 13 & 82 & 2 & 13 & 1 & 6 & 0 & 0 \\
\hline Yes $^{\ddagger}$ & 5 & 3 & 60 & 2 & 40 & 0 & 0 & 0 & 0 \\
\hline Total & 129 & 104 & 81 & 8 & 6 & 14 & 11 & 3 & 2 \\
\hline
\end{tabular}

*includes those cases suitable for outcome assessment; ${ }^{\dagger}$ Differences in cure proportion were not statistically significant by $\chi^{2}$ ( $\left.P=0.8\right)$; $¥ P$ ercentages may add up to be greater than $100 \%$ because of rounding

There were three relapses among 104 cases initially treated to cure within a six-month disease-free interval. The estimated incidence of relapse was 8.1 cases (95\% CI 1.7 to 23.7 ) per 1000 person years of follow-up. They were without comorbidity and were fully sensitive, although one case had TB disease elsewhere. After retreatment, all cases were cured.

Six cases with HIV coinfection were men, 30 to 44 years old, and without associated comorbidity. However, four of these cases had active TB elsewhere. All TBL in HIV coinfected cases were confirmed by culture with only one case of drug resistance (isoniazid, ethambutol and streptomycin). Only two cases were treated to cure which included the drug resistant case. Of the four noncures: one patient died after six weeks of antituberculosis treatment from multi-organ system failure secondary to advanced AIDS; two cases had incomplete treatment (10 and five months treatment duration with less than $80 \%$ of treatment doses taken, both absconded and were lost to follow-up); and one case was in the fourth month of ongoing treatment at the time of data collection.

\section{DISCUSSION}

The number of TBL cases identified in Manitoba per year varied during the study period. A single enlarged cervical lymph node was the most common presentation, with symptoms localized to the involved lymph node site. This has been well described in the literature (5-7,19-23).

In light of the HIV epidemic and drug resistance, it is important that respiratory physicians remain aware of the extrapulmonary manifestations of TB. While other studies have focused on peripheral TBL disease alone, this study included cases of TBL with a site of active TB elsewhere $(6,20,21)$. We found $18 \%$ of our TBL cases with active TB documented elsewhere, both in HIV-infected and uninfected individuals (22). This finding reflects the widespread dissemination of TB, yet TBL is often the sole clinical manifestation. Evidence of TBL should alert health care providers to the possibility of infectious pulmonary TB.

This population-based study shows a higher incidence of TBL in status Aboriginal and the foreign-born populations than in the Canadian-born/nonstatus Aboriginal population.
The incidence in the Canadian-born/nonstatus Aboriginal population is similar to that found in the native German population in a recent study (24). Incidence in status Aboriginals may be higher because of comorbidity: $51 \%$ of status Aboriginal cases had comorbidity in comparison with 33\% of the Canadian-born/nonstatus Aboriginal cases and 12\% of the foreign-born cases. However, with TBL cases and comorbidity removed from the analysis, the incidence of TBL in status Aboriginals is still higher than the Canadian-born/nonstatus Aboriginal cases, possibly reflecting TB disease prevalence within this community.

The proportion of TBL cases from the Western Pacific region $(46 \%)$ and the proportion of foreign-born from the Western Pacific region (80\%) in our study contrasts with the immigration profile of Manitoba, which indicated that only $21 \%$ of all foreign-born immigrants were from the Western Pacific WHO region at the time of the study (3). The high incidence is unlikely the result of immigration surveillance because only $29 \%$ of TBL cases were diagnosed within three years of arrival in Canada. The high incidence of TBL in the foreign-born may reflect the incidence of TBL in the country of origin yet the reasons for this geographical variability remain unknown. It may be due to specific TB strains found in the country of origin or a genetically conditioned response to infection with TB.

Women were more than twice as likely to develop TBL in our study $(5,10,19,23,25)$. Age at diagnosis varied with ethnicity but not sex. The highest incidence of TBL was found in status Aboriginal individuals more than 45 years of age followed by the foreign-born between 15-34 years of age. The high incidence of TBL identified in elderly status Aboriginal women has not previously been described in the literature; TBL has most often been reported in young women originating from countries with high endemic rates of TB $(6,8,10,22,26-29)$. However, in some high-endemic countries men are more often affected, especially in childhood (17,30-32). Cases of TBL in younger, foreign-born patients may illustrate the age of the TB epidemic within this community $(9,25,33)$. When $T B$ is endemic, disease tends to arise in young persons and the majority of cases represent new infections $(25,33)$. In low prevalence 
regions, reactivation of $\mathrm{TB}$ accounts for many cases and $\mathrm{TB}$ is found more often in older patients with identifiable risk factors. Our results mirror this distribution, although determination of new active disease versus reactivation was difficult to confirm without accurate historical data and molecular fingerprinting. With respect to foreign-born TBL, it is possible that there is an inherent genetic difference in the clinical expression of TBL or that these ethnic groups are a marker for immunodeficiency. It should be noted that the majority $(71 \%)$ of TBL cases in the foreign-born were diagnosed more than three years from the date of immigration. Given that HIV status was documented for only $27 \%$ of all TBL cases (three cases of HIV coinfected TBL in the foreign-born cases), the full extent of HIV coinfected TBL remains speculative. It is possible that the proportion of HIV coinfected TB is underestimated given that only a small proportion (17.3\% in 2001) of TB cases in Canada have known documented HIV status, despite the fact that HIV testing was recommended by Health Canada in 1994 for all cases of active pulmonary TB (3).

We report a high rate of bacteriological confirmation (78\%) that varies by ethnicity. These differences might be explained by a higher index of suspicion for and experience with $\mathrm{TB}$ in the status Aboriginal population leading to a greater likelihood that clinical samples are sent for TB culture. Mycobacterium spp, known to cause TBL, include members of the $\mathrm{M}$ tuberculosis complex as well as atypical mycobacterium $(10,21,23,25,27,28,34-35)$. All but one culture in this study grew $\mathrm{M}$ tuberculosis. This finding may reflect reporting bias as atypical isolates are reported to the registry in error. Age, geographical location and HIV status influence the atypical mycobacterium identified $(25,27,34)$. Since we chose only to include cases diagnosed on clinical grounds and with positive pathology, it is possible that atypical mycobacterium could be implicated in these cases.

A single $M$ bovis strain was found, which is quite different from studies in Europe, high TB prevalence countries and parts of the United States $(10,35-38)$. The majority of active TB cases in Canada are caused by M tuberculosis (3). M bovis is no longer endemic in Canada due to the pasteurization of milk, use of the tuberculin test and the slaughter policies in cattle (25). Airborne transmission of $M$ bovis is well documented, even though the association between $M$ bovis and cervical TBL was originally described from exposure to infected unpasteurized milk. In the United States, M bovis-related disease has been found in children of Hispanic origin with extrapulmonary TB (lymph node and abdominal are most common) $(36,37)$. The single case of $M$ bovis TBL in our study was found in an adult foreign-born man. Given the ethnic make-up of our patient population and the fact that the incidence of TBL was lowest in those patients less than 15 years of age, the detection of a single strain of $\mathrm{M}$ bovis is not unexpected. With a high rate of bacteriological confirmation (78\%) in this study, the bacteriology reported is likely representative of TBL cases in our patient population.

Positive pathology alone and clinical diagnoses were included in this analysis and reflect the variable management of TBL at our institution. With positive pathology alone (acidfast bacillus positive and/or granulomas identified), case management is limited by the lack of sensitivities with which to guide treatment. The outcome study identified $9 \%$ of TBL cases (11 of 129 cases) on clinical grounds alone; positive Mantoux test (greater than $10 \mathrm{~mm}$ ) and cervical lymphadenopathy that regressed with antituberculous treatment. Clinical diagnoses were included because empirical treatment can be an acceptable option in the appropriate clinical context as some patients may even refuse investigations, which should not preclude treatment if clinically indicated. Even a percentage of pulmonary TB cases remain culture negative (10\% to $15 \%)$ with empirical antituberculous treatment based on symptoms and abnormal chest $\mathrm{x}$-ray findings suggestive of active TB. Although it is possible that these clinical cases could have had positive cultures or pathology at extranodal sites, all available clinical and laboratory data were collected for each case, regardless of its source.

Obtaining an adequate clinical specimen for culture and sensitivity testing is paramount in the management of pulmonary and extrapulmonary TB. In the case of TBL, this can be accomplished by an FNA or excision biopsy of the involved lymph node. However, histological evidence of granulomatous change does not absolutely distinguish atypical mycobacterium from M tuberculosis. Methods of diagnostic sampling often depend on available medical expertise and laboratory procedures. Both methods are felt to be similarly effective in obtaining sufficient lymph node tissue for histological and microbiological examination for diagnosis, and FNA, in combination with a tuberculin skin test, can increase sensitivity to $90 \%$ (24). For this study, we did not collect information on the specific method of sampling as this was not well documented in the charts reviewed for our pilot study. Clinical samples, regardless of route of sampling, should be sent for acid-fast bacillus smear, culture and histology to increase the probability of an accurate diagnosis. Clinicians are reminded that tissue specimens for the culture of TB should be placed in sterile saline and delivered promptly to the laboratory. Only those clinical samples to be processed for histology should be placed in formalin.

Appropriate treatment of TBL relies on accurate bacteriological identification and six to nine months of combination therapy has been reported effective $(5,14-17)$. The duration of treatment and the definition of successful treatment remain somewhat controversial for TBL because the natural course of TBL may not reflect a clinical cure, and the microbiological confirmation of cure is impractical. New lymph nodes may appear, involved lymph nodes can increase in size and sinus tracts may form despite appropriate therapy $(9,23)$. Regression of lymphadenopathy may continue for years post-treatment and some patients are left with residual palpable nodes or rarely, the development of new lymph nodes in the absence of confirmed microbiological or histological relapse (23). For this reason, the determination of cure often relies on the absence of recurrent or relapsed disease. The retrospective nature of this study did not allow for the detailed collection of data on clinical course during treatment. There was also limited documentation of follow-up after the discontinuation of treatment for the majority of cases. For this reason, specific data on the course of disease during treatment, including paradoxical deterioration and persistent or progressive lymph node disease, was not available. However, we did identify three relapsed cases in 
which clinical deterioration occurred after an initial curative regimen. Two of these relapses were diagnosed on clinical grounds and all responded to retreatment with antituberculous medications. It is possible that these two relapsed cases diagnosed on clinical grounds alone may well have improved in the absence of retreatment.

This study defined TBL cases that were successfully treated or cured as those cases where more than $80 \%$ of prescribed doses were taken in the context of clinical regression of lymphadenopathy $(14,18)$. We defined standard and nonstandard treatment regimens to identify those cases that received optimal treatment; higher cure rates were found with standard treatment. These definitions, though subject to criticism, encompass the key elements of TB treatment: multiple antituberculous drugs for an appropriate duration. Our overall rate of cure $(81 \%)$ was comparable with the literature $(17,34)$. However, we documented eight deaths during treatment (the majority HIV negative) which was troubling when compared with the literature $(15,16,29,34,39,40)$. It is likely that cure rates and deaths were affected by burden of TB disease and comorbidity highlighting the importance of screening for active TB elsewhere. It is probable that treatment failures and relapses reflect the influence of patient compliance, but this study was not designed to assess adherence to treatment. Due to the retrospective nature of this study, the reasons why clinicians chose to treat with less than three drugs in the intensive phase of treatment or less than six months of treatment in total was often unclear. However, patient nonadherence and old age could explain some of these treatment decisions but this is speculative.

Finally, the number of cases with HIV and TB coinfection was small compared with countries with a higher prevalence of TB $(22,41,42)$. Only two cases completed treatment satisfactorily and were discharged from regular follow-up. With these small numbers, we have no firm sign that HIV infection increases the risk of TBL. However, the lower cure rate may suggest that HIV infection interfered with outcome. It is quite possible that the majority of HIV results obtained during the study period (at least before 1994) were from patients with risk factors associated with HIV or a prior HIV/AIDS diagnosis who presented to medical attention with an enlarged lymph node. Given that extrapulmonary TB is more common in HIV coinfected cases of TB, and TBL is identified as the most common site of extrapulmonary TB, the proportion of coinfection identified in this study may simply illustrate this well-known association.

TB of the peripheral lymph nodes remains a common cause of extrapulmonary TB in Manitoba. Vigilance for TB, with health care workers trained to maintain a high-index of suspicion, is key to its eradication. Respiratory physicians, responsible for the majority of TB management, need to be aware that TB remains an important and treatable cause of enlarged lymph nodes.

ACKNOWLEDGEMENTS: The authors thank Ms Kate Wooldrage from the University of Manitoba for her assistance in data extraction and statistical analysis, and Dr Mark FitzGerald for his thoughtful comments regarding this manuscript.

\section{REFERENCES}

1. World Health Organization. Information Fact Sheet No.104; Tuberculosis (Revised March 2004) < www.who.int/mediacentre/ factsheets/fs104/en/> (Version current at May 20, 2004).

2. World Health Organization. Global Tuberculosis Control Annual Report (2001) <www.who.int/gtb/publications/globerep01> (Version current at May 20, 2004).

3. Health Canada. Annual Reports Tuberculosis in Canada. (1996-2001) <www.hc-sc.gc.ca/pphb-dgspsp/publications_2_e.html> (Version current at May 26, 2004).

4. Annual Reports of the Sanatorium Board of Manitoba, 1990-2000.

5. Artenstein AW, Kim JH, Williams WJ, Chung RC. Isolated peripheral tuberculous lymphadenitis in adults: current clinical and diagnostic issues. Clin Infect Dis 1995;20:876-82.

6. Enarson DA, Ashley MJ, Gryzybowski S, Ostapkowicz E, Dorken E. Non-respiratory tuberculosis in Canada. Epidemiologic and bacteriologic features. Am J Epidemiol 1980;112:341-51.

7. Fanning A. Extrapulmonary Tuberculosis. CMAJ 1999;160:1597-1603.

8. Chen TM, Lee PY, Perng RP. Extrapulmonary tuberculosis: Experience at Veterans General Hospital-Taipei, 1985 to 1987. J Formos Med Assoc 1991;90:1163-70.

9. Saraiya M, Binkin NJ. Tuberculosis Among Immigrants. In: Reichman LB, Hershfield ES. Tuberculosis: A comprehensive international approach. Lung Biology in Health and Disease; Volume 66. New York: Marcel Dekker Inc., 1993:661-92.

10. Grange J, Collins C, Yates M. Bacteriological survey of tuberculous lymphadenitis in southeast England, 1973-1980. J Epidemiol Community Health 1982;36:157-61.

11. Njoo H, Long R. The Epidemiology of Tuberculosis in Canada. In: Long R. Canadian Tuberculosis Standards. 5th edn. 2000:3-14.

12. Kent PT, Kubica GP. Public Health Mycobacteriology: A Guide for the Level III Laboratory, 1985.

13. Grange JM, Yates MD, de Kantor IN. Guidelines for speciation within the Mycobacterium tuberculosis complex. Second Edition. $<$ www.who.int/emc-documents/zoonoses/whoemczoo964c.html> (Version current at May, 2004).

14. American Thoracic Society. Treatment of Tuberculosis and Tuberculosis Infection in Adults and Children. Am J Respir Crit Care Med 1993;149:S1-25.

15. McCarthy OR, Rudd RM. Six months chemotherapy for lymph node tuberculosis. Respir Med 1989;83:425-7.

16. Campbell IA, Omerod LP. Six month versus nine months chemotherapy for tuberculosis of the lymph nodes: Final Results. Respir Med 1993;87:621-3.

17. Jawahar MS. Scrofula revisited: An update on the diagnosis and management of tuberculosis of superficial lymph nodes. Indian J Pediatr 2000;67(Suppl 2):S28-33.

18. Menzies D, Pourier L. Diagnosis of Tuberculosis Infection and Disease. In: Long R. Canadian Tuberculosis Standards. 5th edn. Ottawa, Ontario: Health Canada, 2000:45-66.

19. Tomblin JL, Roberts FJ. Tuberculous cervical lymphadenitis. CMAJ 1979;121:324-30.

20. Manolidis S, Frenkiel S, Yoskovitch A, Black M. Mycobacterial infections of the head and neck. Otolaryngol Head Neck Surg 1993;109(3Pt1):427-33.

21. Martin T, Hoeppner VH, Ring ED. Superficial mycobacterial lymphadenitis in Saskatchewan. CMAJ 1998;138:431-4.

22. Cowie RL, Sharpe JW. Extra-pulmonary tuberculosis: a high frequency in the absence of HIV infection. Int J Tuberc Lung Dis 1997;1:159-62.

23. Grzybowski S, Allen EA. History and importance of scrofula. Lancet 1995;346:1472-4.

24. Geldmacher H, Taube C, Kroeger C, Magnussen H, Kirsten, DK. Assessment of lymph node tuberculosis in Northern Germany. Chest 2002;121:1177-82.

25. Sloane MF. Mycobacterial Lymphadenitis. In: Rom WN, Garay SM. Tuberculosis. Boston: Little, Brown and Company (Inc), 1996:577-84.

26. Chen YM, Lee PY, Su WJ, Perng RP. Lymph node tuberculosis: 7 -year experience in Veterans General Hospital, Taipei, Taiwan. Tuber Lung Dis 1992;73:368-71.

27. Pang SC. Mycobacterial lymphadenitis in Western Australia. Tuber Lung Dis 1992;73:362-7.

28. Wilkins EG, Roberts C. Superficial tuberculous lymphadenitis in Merseyside: 1969-1984. J Hyg (Lond) 1985;95:115-22. 
29. Summers GD, McNicol MW. Tuberculosis of superficial lymph nodes. Br J Dis Chest 1980;74:369-73.

30. Qazi SA, Khan S, Khan MA. Epidemiology of childhood tuberculosis in a hospital setting. J Pak Med Assoc 1998;48:164-7.

31. Seth V, Kabra SK, Jain Y, Semwal OP, Mukhopadhyaya S, Jensen RL. Tubercular lymphadenitis: Clinical manifestations. Indian J Pediatr 1995;62:565-70.

32. Memish ZA, Mah MW, Mahmood SA, Bannatyne RM, Khan MY. Clinico-diagnostic experience with tuberculous lymphadenitis in Saudi Arabia. Clin Microbiol Infect 2000;6:137-41.

33. Grigg ERN. The arcana of tuberculosis. Am Rev Tuberc 1958;78:151-72.

34. Wark P, Goldberg H, Ferson M, McKenzie D, Lau E, Rivas K. Mycobacterial lymphadenitis in eastern Sydney. Aust N Z J Med 1998;28:453-8.

35. Yates MD, Grange JM. Bacteriological survey of tuberculous lymphadenitis in southeast England, 1981-1989. J Epidemiol Community Health 1992;46:332-5.

36. Dankner WM, Davis CE. Mycobacterium bovis as a significant cause of tuberculosis in children residing along the United StatesMexico Border in the Baja California region. Pediatrics 2000;105:1-5.
37. Dankner WM, Waecker NJ, Essey MA, et al. Mycobacterium bovis infections in San Diego: A clinicoepidemiologic study of 73 patients and a historical review of a forgotten pathogen. Medicine 1993;72:11-37.

38. Kazwala RR, Daborn CJ, Sharp JM, et al. Isolation of Mycobacterium bovis form human cases of cervical adenitis in Tanzania: A cause for concern? Int J Tuberc Lung Dis 2001;5:87-91.

39. Omerud LP, Bentley C. The management of lymph node tuberculosis notified in England and Wales in 1993. J R Coll Physicians Lond 1997;31:666-8.

40. Xie HJ, Enarson DA, Chao CW, Allen EA, Grzybowski S. Deaths in tuberculosis patients in British Columbia, 1980-1984. Tuber Lung Dis 1992;73:77-82.

41. Shriner KA, Mathisen GE, Goetz MB. Comparison of mycobacterial lymphadenitis among persons infected with human immunodeficiency virus and seronegative controls. Clin Infect Dis 1992;15:601-5.

42. Bem C. Human immunodeficiency virus-positive tuberculous lymphadenitis in Central Africa: clinical presentation of 157 cases. Int J Tuberc Lung Dis 1997;1:215-9. 


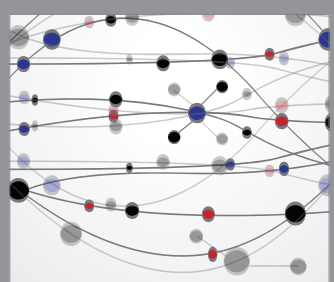

The Scientific World Journal
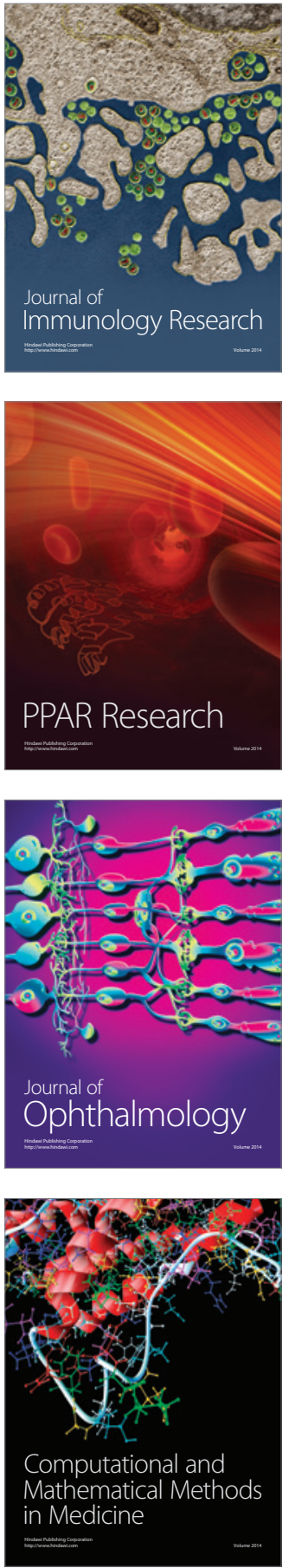

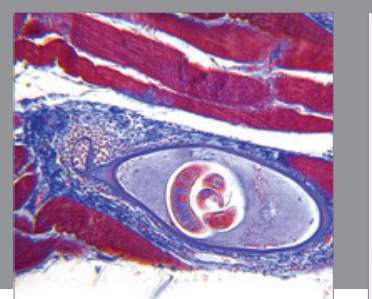

Gastroenterology Research and Practice

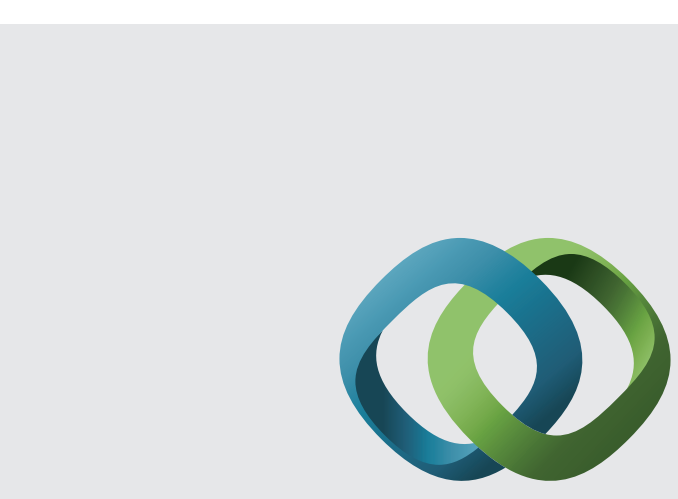

\section{Hindawi}

Submit your manuscripts at

http://www.hindawi.com
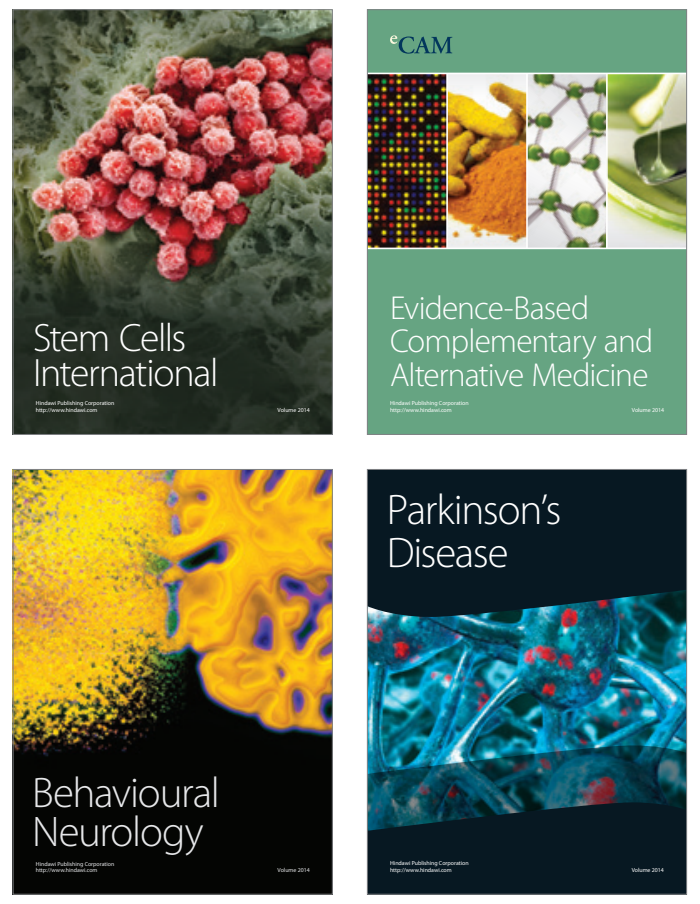
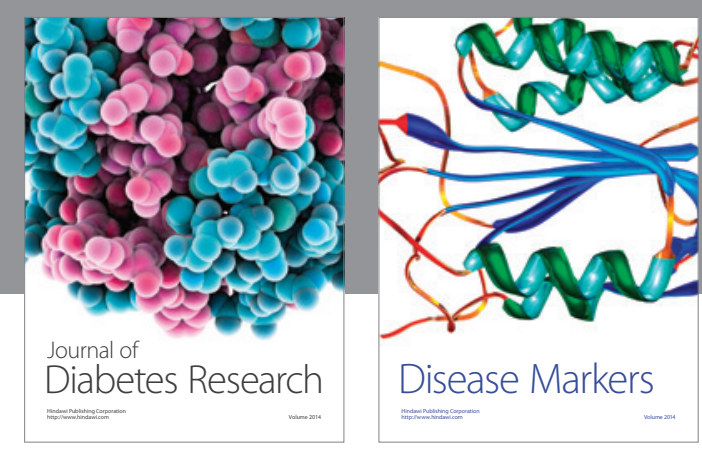

Disease Markers
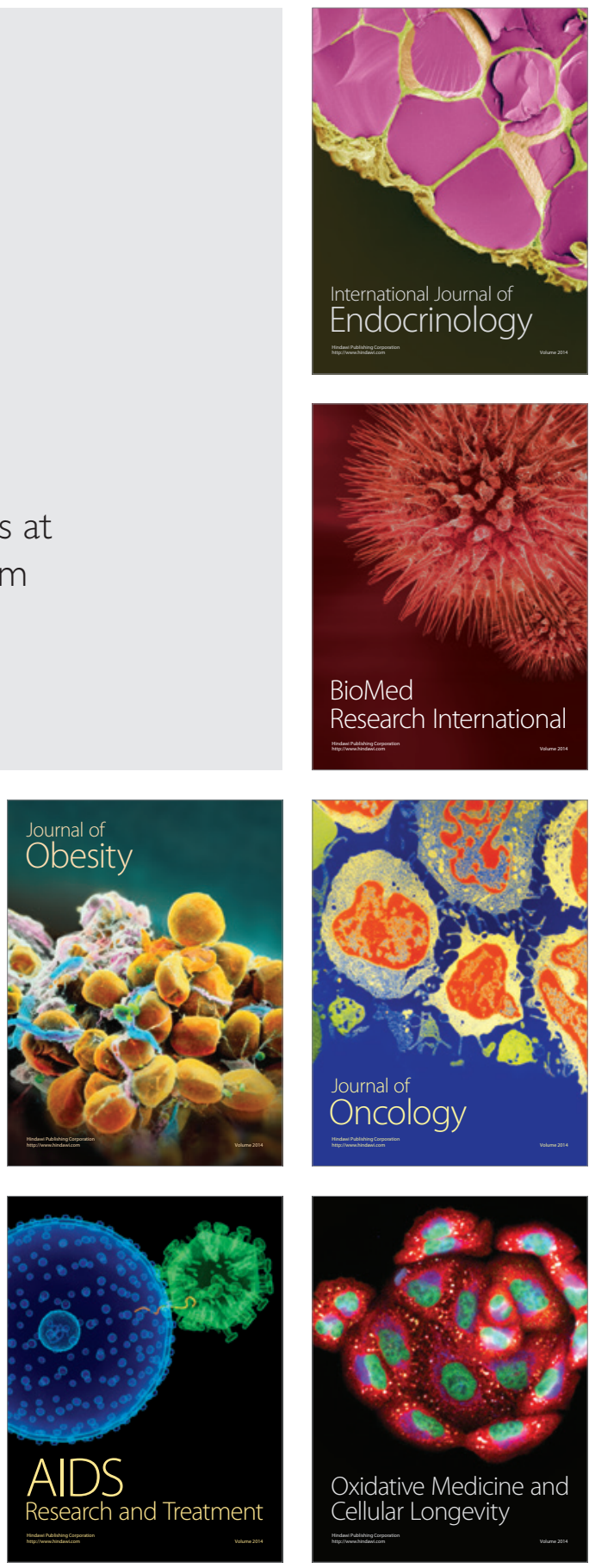